\title{
Max Tech Efficiency Electric HPWH with Low-GWP Halogenated Refrigerant
}

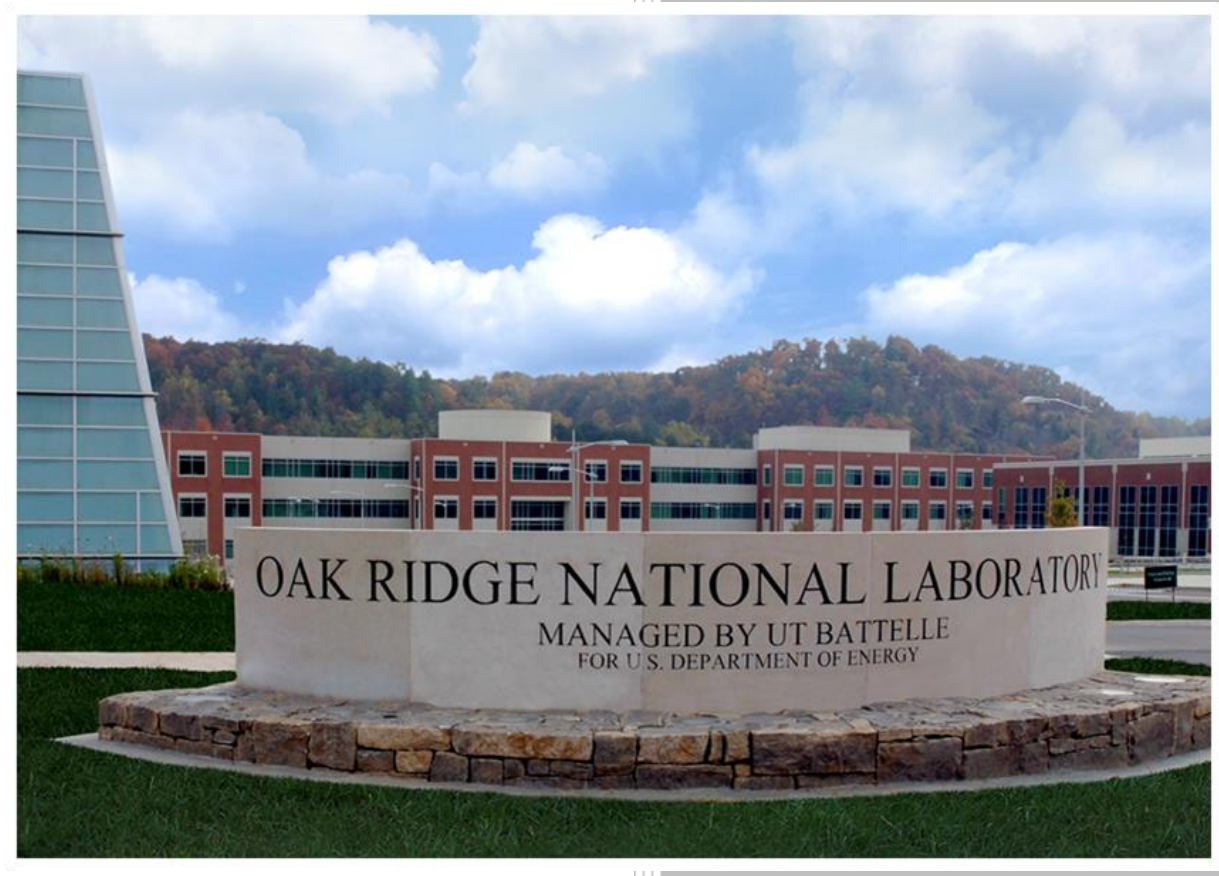

Kashif Nawaz

Bo Shen

Ahmed Elatar

Van Baxter

Approved for public release. Distribution is unlimited
November 28, 2016 


\title{
DOCUMENT AVAILABILITY
}

Reports produced after January 1, 1996, are generally available free via US Department of Energy (DOE) SciTech Connect.

Website http://www.osti.gov/scitech/

Reports produced before January 1, 1996, may be purchased by members of the public from the following source:

\author{
National Technical Information Service \\ 5285 Port Royal Road \\ Springfield, VA 22161 \\ Telephone 703-605-6000 (1-800-553-6847) \\ TDD 703-487-4639 \\ Fax 703-605-6900 \\ E-mail info@ntis.gov \\ Website http://www.ntis.gov/help/ordermethods.aspx
}

Reports are available to DOE employees, DOE contractors, Energy Technology Data Exchange representatives, and International Nuclear Information System representatives from the following source:

Office of Scientific and Technical Information

PO Box 62

Oak Ridge, TN 37831

Telephone 865-576-8401

Fax 865-576-5728

E-mail reports@osti.gov

Website http://www.osti.gov/contact.html

This report was prepared as an account of work sponsored by an agency of the United States Government. Neither the United States Government nor any agency thereof, nor any of their employees, makes any warranty, express or implied, or assumes any legal liability or responsibility for the accuracy, completeness, or usefulness of any information, apparatus, product, or process disclosed, or represents that its use would not infringe privately owned rights. Reference herein to any specific commercial product, process, or service by trade name, trademark, manufacturer, or otherwise, does not necessarily constitute or imply its endorsement, recommendation, or favoring by the United States Government or any agency thereof. The views and opinions of authors expressed herein do not necessarily state or reflect those of the United States Government or any agency thereof. 
Energy and Transportation Sciences Division

\title{
MAX TECH EFFICIENCY ELECTRIC HPWH WITH LOW-GWP HALOGENATED REFRIGERANT
}

\author{
Kashif Nawaz \\ Bo Shen \\ Ahmed Elatar \\ Van Baxter
}

Date Published: 11-28-2016

\author{
Prepared by \\ OAK RIDGE NATIONAL LABORATORY \\ Oak Ridge, TN 37831-6283 \\ managed by \\ UT-BATTELLE, LLC \\ for the \\ US DEPARTMENT OF ENERGY \\ under contract DE-AC05-00OR22725
}




\section{CONTENTS}

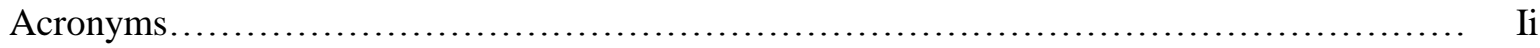

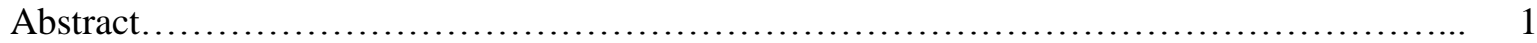

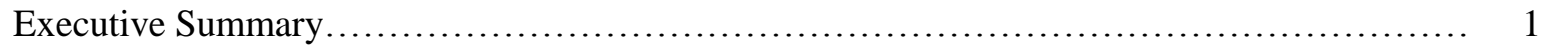

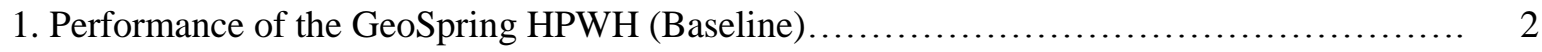

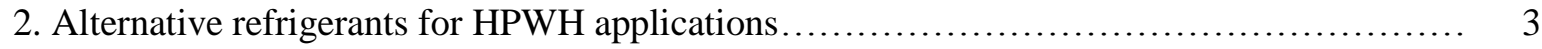

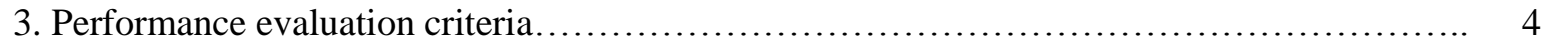

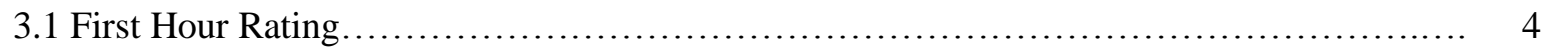

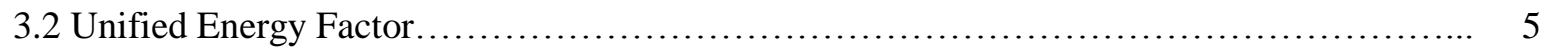

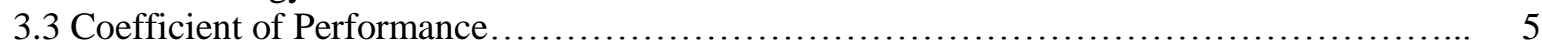

4. Heat Pump Water Heater Modeling ................................................ 5

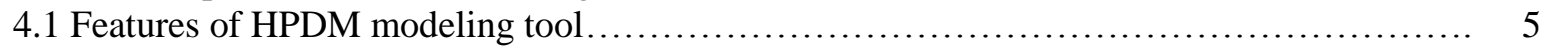

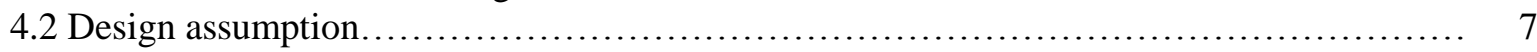

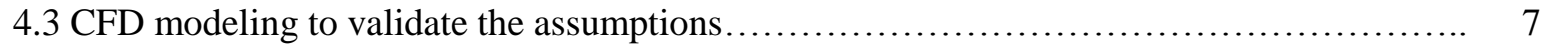

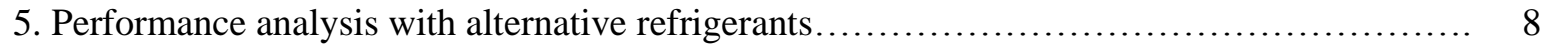

5.1 Parameters for performance evaluation............................................ 9

5.2 First Hour Rating for different refrigerants and design parameters..................... 10

5.3 Unified Energy Factor for different refrigerants and design parameters .................. 11

5.4 Coefficient of Performance for different refrigerants and design parameters.............. 12

6. Comparison of performance to current HPWH systems................................ 13

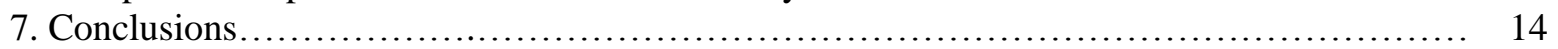

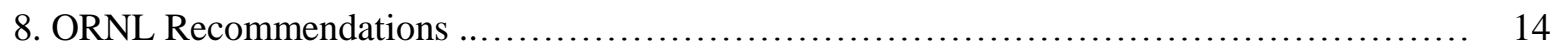

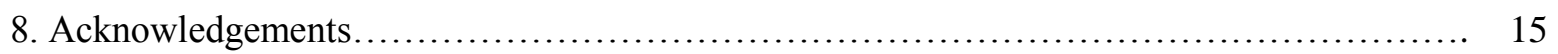

9. References................................................................. 15

Appendix A -Additional performance evaluation parameters $\quad \ldots \ldots \ldots \ldots \ldots \ldots \ldots \ldots \ldots \ldots \ldots . \ldots \ldots$ 


\section{ACRONYMS}

HPDM Heat Pump Design Model

HPWH Heat Pump Water Heater

HFO Hydroflouroolefin

CFD Computational Fluid Dynamics

GWP Global Warming Potential

BTO Building Technology Office

FHR First Hour Rating

UEF Unified Energy Factor

COP Coefficient of Performance

FEMP Federal Energy Management Program 


\begin{abstract}
A scoping-level analysis was conducted to determine the maximum performance of an electric heat pump water heater (HPWH) with low GWP refrigerants (hydroflouroolefins (HFO), hydrofluorocarbons (HFC), and blends). A baseline heat pump water heater (GE GeoSpring) deploying R-134a was analyzed first using the DOE/ORNL Heat Pump Design Model (HPDM) modeling tool. The model was calibrated using experimental data to match the water temperature stratification in tank, first hour rating, energy factor and coefficient of performance. A CFD modeling tool was used to further refine the HPDM tank model. After calibration, the model was used to simulate the performance of alternative refrigerants. The parametric analysis concluded that by appropriate selection of equipment size and condenser tube wrap configuration the overall performance of emerging low GWP refrigerants for HPWH application not only exceed the Energy Star Energy Factor criteria i.e. 2.20, but is also comparable to some of the most efficient products in the market.
\end{abstract}

\title{
EXECUTIVE SUMMARY
}

This report describes results of a scoping-level analysis to establish and maximize the efficiency of electric heat pump water heaters (HPWH) with emerging low GWP HFO and HFC alternatives to conventional refrigerants (R-134a). The specific goal of the work was to evaluate the feasibility of alternative refrigerants while analyzing different design options to optimize the system's performance. This effort was undertaken in response to a clearly expressed target in the FY10 DOE Building Technology Office (BTO) Statement of Needs for the water heating (WH) program element. Specifically, there has been an emphasis on designing the heat pump water heaters which are highly efficient compared to electric resistance or gas-fired water heaters. With the phase-out of conventional refrigerants including $\mathrm{R}-134 \mathrm{a}$, it is critical to evaluate the performance of alternative refrigerants which can potentially be a successful drop-in-replacement.

A preliminary analysis was conducted to short-list five low GWP refrigerants (R1234yf, R1234ze, R152a, $\mathrm{R} 510 \mathrm{a}$ and R512a) with comparable thermodynamic properties to the baseline (R-134a). In order to determine the first hour rating (FHR) and 24-hour unified energy factor (UEF), an HPDM model was developed where a wrapped tube condenser heats up a stratified water tank. Two auxiliary electric heaters and a control strategy (as was the case for baseline system - a GE GeoSpring HPWH) were added in the model to operate when the heat pump cannot provide the enough energy to meet the demand. CFD modeling provided ancillary information to confirm processes such water temperature stratification and "backflow effect" causing mixing during water draw events. The model was calibrated with experimental data obtained during earlier evaluations of the baseline design (Murphy, et al. 2011; Baxter, et al, 2016). Comparable performance was achieved by the calibrated model for the baseline when compared to the measurements. The calibrated model was then used to run a parametric analysis where refrigerants and system parameters including condenser tube wrap pattern, evaporator size, heat leak from tank and condenser tube diameter were varied to maximize the unified energy factor (UEF) based on the draw pattern recommended by DOE (Docket No. EERE-2011-BT-TP-0042).

It was concluded that all the examined refrigerants with the varied design parameters fall under the medium usage group (Table 3) based on the first hour rating. The highest energy factor $(\sim 3.60)$ was achieved for parallel wrap configurations, with the same condenser tube size as the baseline (0.31-inch OD?) and a relatively larger evaporator size and higher tank insulation effectiveness. Among different alternative refrigerants, all showed a comparable UEF except R1234ze which had a slightly lower performance and showed consistently lower UEF under all design conditions. To summarize, multiple refrigerants showed promising results when compared to the baseline. An interesting aspect of the study is 
the drop-in-replacement approach in which system design modifications required to use the alternatives will not be significant. A validation through experiments with selected alternative refrigerants is recommended based on the highly promising findings.

\section{PERFORMANCE OF GEO-SPRING HPWH (BASELINE ANALYSIS)}

GE GeoSpring HPWH was considered as the baseline water-heating unit for performance evaluation and model calibration. The performance of this unit has been evaluated during a previous study at ORNL (Murphy, et al. 2011; Baxter, et al, 2016). The main reasons for selecting this unit as the baseline were its good energy efficiency, available product information, and availability of extensive test data for calibration of the various modules of the HPDM simulation tool. The UEF for the latest model is about 3.19 which exceeds the minimum UEF criteria required for the Energy Star label (UEF=2.2) and thus is a good representation of most the efficient products available in market. Figure 1 shows the schematics for the system and details of instrumentation.

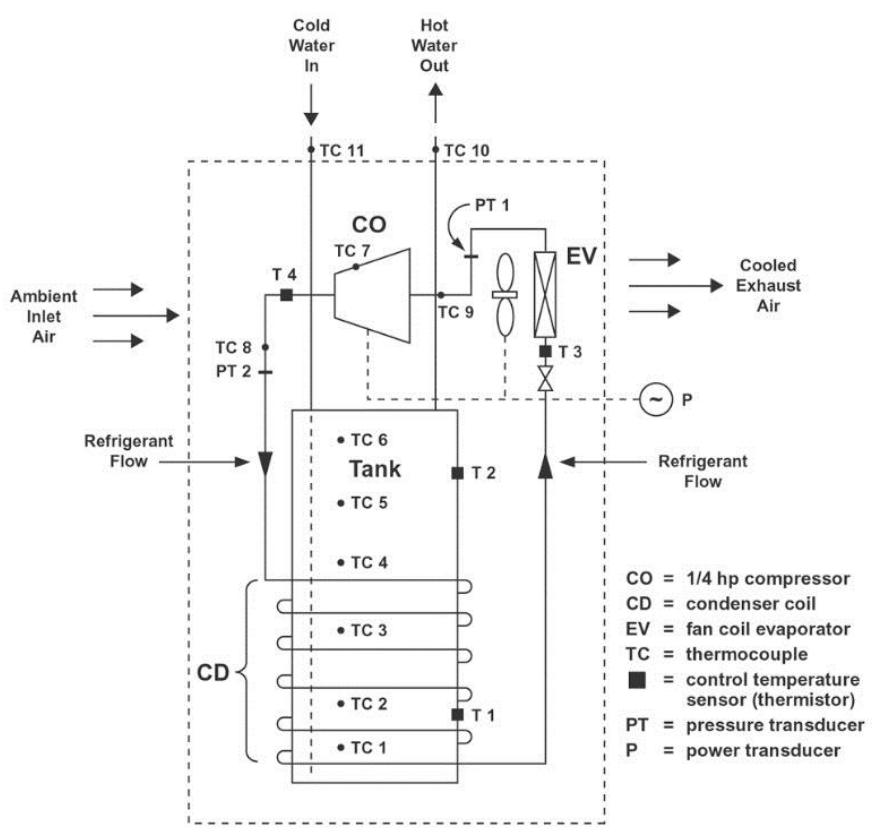

Figure 1. Schematic of instrumentation for GE GeoSpring HPWH

GE GeoSpring heat pump water heater included two auxiliary electric resistance heaters installed on lower and upper sides of the tank. These heaters are activated only when the heat pump is unable to meet the demand or cannot operate at all. HPDM simulations were run according to the prescribed experimental conditions and the model was calibrated to match the test results including water temperature stratification, energy factor (EF) and FHR. Figure 2 shows the relative comparison of measured and predicted values for top and bottom node temperatures in the water tank. A clear observation is the water stratification measured by experiments and predicted by the simulation. The calibrated model was able to match the test data well. The FHR rating was established as 62 gallons (close to the predicted values of 60 gallons) and the energy factor was calculated as 3.20 for parallel refrigerant flow and 3.18 for counter flow when a $10 \%$ tank heat loss (or skin factor) was used along with 
$0.15 \%$ heat loss from bulk mixing during water draw in addition to mixing occurring due to natural convection. This EF was fairly close to the measured values of 3.19.

It is important to note that for these baseline analyses and model calibrations, the FHR and EF metrics were based on the pre-2015 DOE test method for water heaters (US Code of Federal Regulations, 2010). The HPDM simulations used the same method to be consistent. However, for the simulations described in the remainder of this report the metrics UEF and FHR based on the new test method prescribed by DOE were utilized (DOE 2013). Details can found in the following sections.

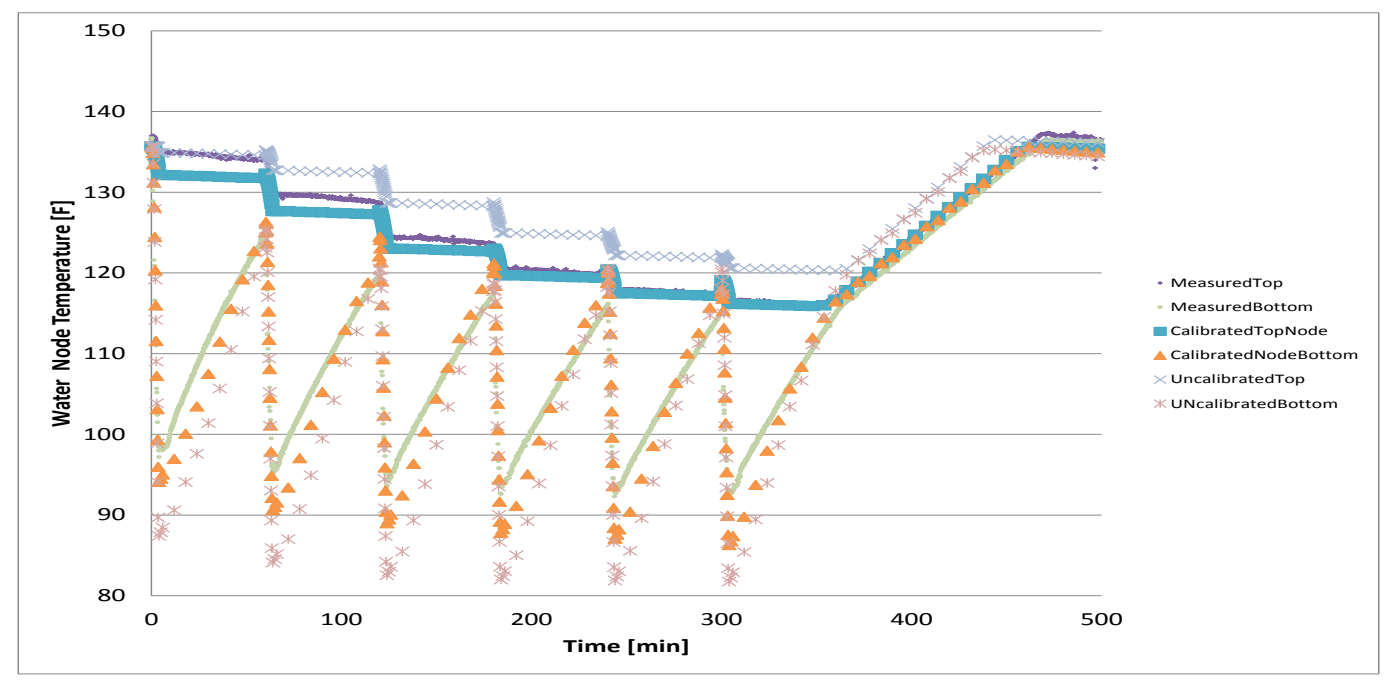

Figure 2. Temperature stratification variation (measured vs. predicted behavior)

\section{ALTERATIVE REFRIGERANTS FOR HPWH APPLICATIONS}

There are multiple models for residential and commercial HPWHs being manufactured by the relevant industry with varying capacity and efficiency. However most of the existing products use R-134a as the refrigerant. The conventional refrigerant has provided acceptable efficiency and when we start seeking a replacement perhaps the ideal scenario is to propose a refrigerant which does not require significant modification of the existing system configurations. A drop-in-replacement refrigerant resulting in a measureable increment in the performance will be an ideal candidate. In order to short-list appropriate refrigerants an extensive list of potential candidates was considered. The following table lists the refrigerants down-selected for further analysis in this study. It can be observed that most of the refrigerants have comparable properties to R-134a such as critical temperature and pressure and volumetric capacity.

Table 1: Alternative refrigerants for HPWH applications

\begin{tabular}{|c|c|c|c|c|c|c|c|c|}
\hline \multirow[t]{2}{*}{ Refrigerant } & \multirow{2}{*}{$\begin{array}{c}\text { Composition } \\
\text { (mass \%) }\end{array}$} & \multirow[b]{2}{*}{$\mathrm{T}_{\mathrm{c}}(\mathrm{K})$} & \multirow[b]{2}{*}{$\mathrm{P}_{\mathrm{c}}(\mathrm{Mpa})$} & \multicolumn{4}{|c|}{ at $45 \mathrm{~F}(280.37 \mathrm{~K})$} & \multirow{2}{*}{$\begin{array}{c}\text { at } 155 \mathrm{~F} \\
(341.48 \mathrm{~K}) \\
\mathrm{P}_{\mathrm{sat}}(\mathrm{Mpa})\end{array}$} \\
\hline & & & & $\mathrm{P}_{\mathrm{sat}}(\mathrm{Mpa})$ & $\mathrm{h}_{\mathrm{fg}}(\mathrm{KJ} / \mathrm{kg})$ & $\rho_{\text {vap }}\left(\mathrm{kg} / \mathrm{m}^{3}\right)$ & $\begin{array}{l}\text { Vol. Cap } \\
\left(\mathrm{KJ} / \mathrm{m}^{3}\right)\end{array}$ & \\
\hline R134a & Pure & 374.21 & 4.06 & 0.3774 & 193.17 & 18.66 & 3604.55 & 2.04 \\
\hline R510a & $\begin{array}{c}\text { RE170(88.0\%) } \\
\text { R600a(12\%) }\end{array}$ & 398.82 & 5.12 & 0.3402 & 411.591 & 7.521 & 3095.58 & 1.7222 \\
\hline R512a & $\begin{array}{c}\mathrm{R} 134 \mathrm{a}(5.0 \%) \\
\mathrm{R} 152 \mathrm{a}(95.0 \%)\end{array}$ & 385.99 & 4.50 & 0.3396 & 294.61 & 10.843 & 3194.46 & 1.821 \\
\hline R152a & Pure & 386.41 & 4.52 & 0.3396 & 299.59 & 10.647 & 3189.74 & 1.8173 \\
\hline R1234yf & Pure & 367.85 & 3.38 & 0.4006 & 158.52 & 22.253 & 3527.55 & 1.9725 \\
\hline
\end{tabular}




\begin{tabular}{|l|l|l|l|l|l|l|l|l|}
\hline R1234ze & Pure & 382.51 & 3.64 & 0.2803 & 179.49 & 15.004 & 2693.07 & 1.551 \\
\hline
\end{tabular}

\section{PERFORMANCE EVALUATION CRITERIA}

U.S. Department of Energy (DOE) initiated a rulemaking to consider amendments to its old test procedures for covered residential and commercial water heaters as per recommendation of The American Energy Manufacturing and Technical Corrections Act (AEMTCA). Based on the extensive testing a new performance evaluation procedure was defined. According to the new procedure the set point for water temperature is $125^{\circ} \mathrm{F}$ and the test condition for inlet water and ambient air temperature are prescribed as $58^{\circ} \mathrm{F}$ and $67.5^{\circ} \mathrm{F}(35-45 \%$ relative humidity) respectively. The key performance metrics used to evaluate and compare the performance of water heaters (WH), including HPWHs, are listed below.

\subsection{FIRST HOUR RATING}

First Hour Rating (FHR) is a measure of the available hot water capacity of the WH (in gallons). According to the new DOE test method hot water $\left(125 \pm 15^{\circ} \mathrm{F}\right)$ is drawn from the tank as long as the temperature is $67 \pm 2^{\circ} \mathrm{F}$ higher than the entering water temperature. Once the temperature drops below the prescribed limit, the supply is stopped until the set point of $125 \pm 15^{\circ} \mathrm{F}$ is met again. Following the procedure, the total water drawn from the tank during one hour indicates the total capacity of the heat pump and electric resistance heaters.

\subsection{UNIFIED ENERGY FACTOR}

Unified Energy Factor (UEF) is a measure of the efficiency of the system. It accounts the ratio of total amount of heat gained from the system (by heating the water) to the total power required to operate the system. The previous EF test procedure used a single water draw pattern - six equal water draws of $\sim 10.7$ gallons each spaced equally during the first five hours of the EF test - applied to all WHs (including HPWHs) with a storage tank. In contrast, the new method uses the measured FHR value to define draw pattern. Table 2 provides the details of the draw pattern for a storage water heater based on FHR.

Table 2. Water draw pattern based on FHR

\begin{tabular}{|c|c|c|}
\hline FHR greater or equal to (gals) & FHR less than (gals) & Draw pattern for 24-hr UEF \\
\hline 0 & 20 & Point of use \\
\hline 20 & 55 & Low usage \\
\hline 55 & 80 & Medium usage \\
\hline 80 & Max & High usage \\
\hline
\end{tabular}

When the FHR analysis was conducted, it was concluded that under all parametric conditions the appropriate draw pattern will be for medium usage (FHR varied between 60-65 gallons). Table 3 presents the water draw pattern for a medium usage storage tank. The specified water draw pattern was used to determine the UEF.

Table 3. Medium water draw procedure

\begin{tabular}{|c|c|c|c|}
\hline Draw Number & Time During Test (hh:mm) & $\begin{array}{c}\text { Volume } \\
\text { (gals/L) }\end{array}$ & $\begin{array}{c}\text { Flow Rate } \\
(\text { GPM/LPM) }\end{array}$ \\
\hline 1 & $00: 00$ & $15.0(56.8)$ & $1.7(6.5)$ \\
\hline
\end{tabular}




\begin{tabular}{|c|c|c|c|}
\hline 2 & $00: 30$ & $2.0(7.6)$ & $1(3.8)$ \\
\hline 3 & $01: 40$ & $9.0(34.1)$ & $1.7(6.5)$ \\
\hline 4 & $10: 30$ & $9.0(34.1)$ & $1.7(6.5)$ \\
\hline 5 & $11: 30$ & $5.0(18.9)$ & $1.7(6.5)$ \\
\hline 6 & $12: 00$ & $1.0(3.8)$ & $1(3.8)$ \\
\hline 7 & $12: 45$ & $1.0(3.8)$ & $1(3.8)$ \\
\hline 8 & $12: 50$ & $1.0(3.8)$ & $1(3.8)$ \\
\hline 9 & $16: 00$ & $1.0(3.8)$ & $1(3.8)$ \\
\hline 10 & $16: 15$ & $2.0(7.6)$ & $1(3.8)$ \\
\hline 11 & $16: 45$ & $2.0(7.6)$ & $1.7(6.5)$ \\
\hline 12 & $17: 00$ & $7.0(26.5)$ & $1.7(6.5)$ \\
\hline \multicolumn{3}{|c|}{ Total Volume Drawn Per Day: 55 gallons (208 L) } \\
\hline
\end{tabular}

\subsection{COEFFICIENT OF PERFORMANCE}

Coefficient of performance (COP) is another related criterion which measures the performance of the heat pump. It is important to differentiate between UEF and COP. The system's COP is always higher than the UEF because while determining the COP the energy lost through the tank wall and insulation (also known as skin effect) is also included in the heat supplied by the heat pump and hence results in a larger number. While UEF is the performance of the system based on how much energy is used to heat up the water delivered from the tank, the ultimate goal of the system, COP represents the performance of heat pump only.

\section{HPWH MODELING}

The DOE/ORNL Heat Pump Design Model was used to model the heat pump water heater (HPWH). HPDM is a well-recognized, public-domain HVAC equipment modeling and design tool (http://hpdmflex.ornl.gov/hpdm/wizard/welcome.php). This work draws upon some component modeling aspects of a previous ORNL HPWH analysis for forced-flow designs (Baxter et al, 2011).

\subsection{FEATURES OF HPDM MODELING TOOL}

HPDM has been used for multiple research and development projects across research organizations and industry. Over the past few years the simulation tool has been updated and calibrated with experimental data for numerous studies and is capable of simulating rather complex system configurations accurately which was not possible until more recently. Some of the key features important to the current study are described as following.

\subsubsection{Compressor}

AHRI 10-coefficient compressor maps have been used to calculate mass flow rate and power consumption. This enabled calculation of the refrigerant-side vs. air-side energy balance from inlet to outlet by inputting a compressor shell heat loss ratio relative to the power input. For the baseline study, the original compressor map, developed for R-134a was used. For modeling alternative refrigerants, it was assumed that the compressor would maintain the same volumetric and isentropic efficiencies at the same suction and discharge pressures. Thus, the efficiencies were adjusted from the original R-134a map as a function of the relative suction and discharge pressures of the alternative refrigerants. 


\subsubsection{Evaporator}

HPDM uses a segment-to-segment modeling approach, which divides a single tube into numerous mini segments. Each tube segment has individual air-side and refrigerant-side entering states, and considers possible phase transition; the $\varepsilon$-NTU approach has been used for heat transfer calculations within each segment. Air-side fins are simplified as an equivalent annular fins. Both refrigerant and air-side heat transfer and pressure drop were considered in the study; the coil model can simulate arbitrary tube and fin geometries and circuitries, any refrigerant-side entering and exit states, maldistribution, and accept twodimensional local air-side temperature, humidity and velocity inputs; the tube circuitry and 2-D boundary conditions were provided by an input file. In addition to the functionalities of the segment-to-segment fintube condenser, the evaporator model was capable of simulating the dehumidification process. The method of Braun, et al. (1989) was used to simulate cases of water condensing on an evaporating coil, where the driving potential for heat and mass transfer is the difference between enthalpies of the inlet air and saturated air at the refrigerant temperature. The heat transfer correlation published by Thome (2002) was used to calculate the evaporator two-phase heat transfer coefficient. Air side heat transfer correlations were obtained from Wang (2001), specific to different fin types, e.g. louvered fin, wavy fin, slit fin, etc.

\subsubsection{Wrapped Tank Condenser}

A wrapped-tank condenser model was developed specifically for this investigation, using a segment-tosegment modeling approach. The flow-pattern-dependent heat transfer correlation published by Thome (2003) was used to calculate the condenser two-phase heat transfer coefficient. As for the evaporator, the pressure drop correlation published by Kedzierski (1999) was used to model the two-phase pressure drop. The heat transfer between the refrigerant and water is calculated by considering the forced convection at the refrigerant-side, tube and water tank wall conductance, and water-side natural convection. The coil model simulates temperature and pressure variations in mini-segments along the refrigerant flow direction, and interacts with the node temperatures of a transient, stratified water tank model.

\subsubsection{Stratified Water Tank}

The tank model included the parameters such as thermal conductivity of thermal paste and the insulation covering the tank. Thus the heat loss from the tank was captured for the full time of the operation. The transient tank model accounted for one-dimensional water temperature stratification caused due to the natural convention. Along with the heat transfer from wrapped condenser tube, a simultaneous operation of supplemental electric water heaters was also simulated. These electric heaters are placed to provide continuous hot water supply in the case of heat pump failure or when the heat pump itself cannot provide enough heat to meet the demand. The water tank model divides water mass into 10 nodes (control volumes) in vertical direction. Each water node has uniform temperature and exchanges heat with condenser tubes in the section. The tank model captures the mechanisms of 1) piston flow, i.e. make-up water enters at the bottom and pushes the flow to the supply port at the top; 2) heat conduction between neighboring nodes; and 3) upward flow and mixing caused by natural convection. The buoyancy driven upward flow and heat transfer is simulated by Churchill and Chu (1975). In addition, we innovatively applied an empirical tuning parameter to correlate a backflow mixing effect, i.e. whirls caused by water draw, as shown in Figure 3. The tuning factor enables calibrating the water tank model to match measured water stratifications as indicated in Figure 2.

\subsubsection{Expansion Devices}

The compressor suction superheat degree and condenser subcooling degree were explicitly specified. As such, a specific expansion device control was not modeled and a simple assumption of constant enthalpy expansion was used.

\subsubsection{Fans and Blowers}

The air flow rate and power consumption were direct inputs from the laboratory measurements. 


\subsubsection{Refrigerant Lines}

Heat transfer in a refrigerant line was ignored and the pressure drop was calculated using a turbulent flow model, as a function of the refrigerant mass flux.

\subsubsection{Refrigerant Properties}

In order to establish the thermophysical properties of different refrigerants, instead of using the property call function programmed to call REFPROP 9.1 directly, property look-up tables were generated. The program used 1-D and 2-D cubic spline interpolation algorithms to calculate refrigerant properties via the look-up tables; this greatly boosted the calculation speed without significantly compromising the accuracy.

\subsection{DESIGN ASSUMPTIONS}

Following are the assumptions used for the HPWH simulations:

1- In order to account for potential stratification due to variation of heat flux along the height of the water tank, a multi-node approach was adopted where 10 nodes (length of each node varied according to the wrap pattern) can have a different water temperature based on the boundary heat flux from the fluid passing through the wrapped condenser tube.

2- The radial temperature variation was found to be insignificant except very close to the tank wall? and was not included in the model.

3- The two wrap patterns considered in this study, namely parallel flow and counter flow, presented the following refrigerant flow patterns: 1) flow from top to bottom of the tank wrap (counter flow); and 2) refrigerant enters near the middle of the wrap, moves upwards to the topmost wrap and then returns to the bottom section of the wrap (parallel flow).

4- The so-called backflow effect was included in the modeling where the stratification is disturbed not only by natural convention currents (when the HP is operating and water is being heated) but also due to the mixing caused when the water is drawn from the tank. The calibration factors introduced to represent the phenomena were confirmed by the CFD analysis (see the following CFD analysis section).

5- The resistance heating element (auxiliary source) is turned on only when the heat pump is unable to meet the demand (water leaving temperature is lower then set point).

\subsection{CFD MODELING TO VALIDATE THE ASSUMPTIONS}

\subsubsection{Bulk Mixing During Water Draw.}

It is important to validate and include the bulk mixing occurring during water draw from the tank. In order to validate the assumption, a series of CFD simulations were carried out to observe the impact of mixing due to "backflow effect". Figure 3 represents water velocity streamlines (in $\mathrm{m} / \mathrm{s}$ ) for an adiabatic water tank as the hot water is withdrawn from the top and replenished by cold water entering the tank through the dip tube near the bottom. The bulk mixing happening solely because of "backflow effect" is obvious. It is important to note that all previous modeling approaches including "EnergyPlus" ignore this relatively important phenomena which dominates the natural convention currents but occurs only during water draw events. 

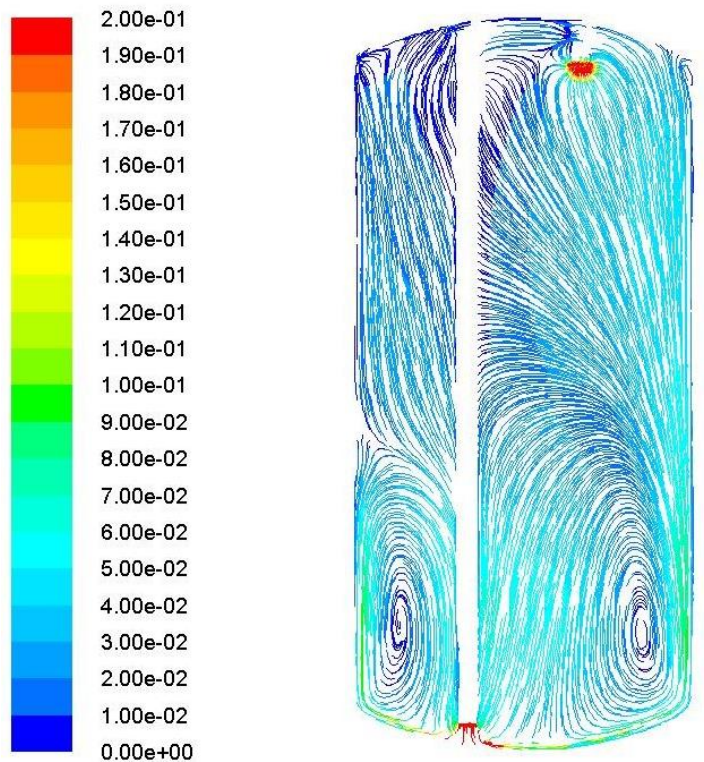

Figure 3. Streamline for water flow in the tank during draw (scale shows velocity-m/s)

\subsubsection{Stratified Temperature Profile in Vertical Direction}

Water stratification caused due to the heat flux is an important aspect of tank modeling as can be seen from the 2-D CFD model of a tank observed during a previous study. As described above, the process was included in HPDM modeling by dividing the tank into various nodes where each node was considered at uniform temperature and neighboring nodes can interact to exchange heat. One important observation from the CFD analysis was the insignificance of radial temperature variation as can be seen in the Figure 4 and hence this was ignored in the HPDM model.

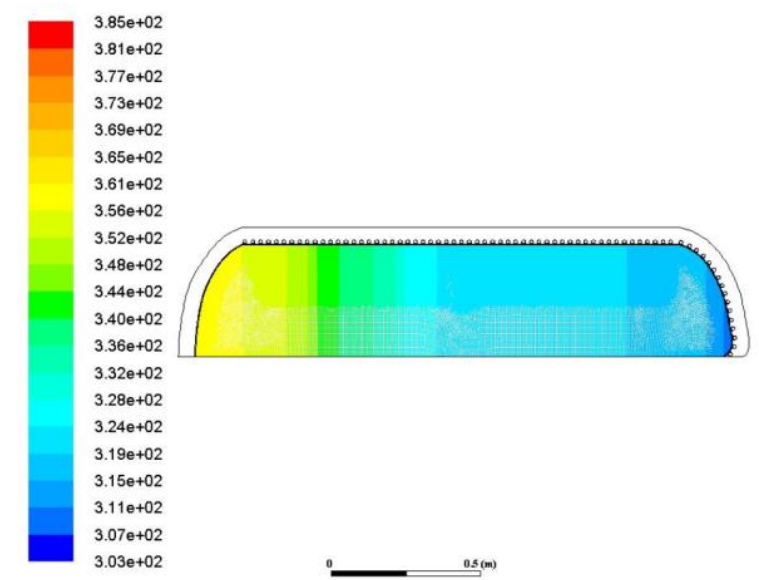

Figure 4. Water temperature profile in the tank (scale shows temperature-K)

\section{PERFORMANCE ANALYSIS WITH ALTERNATIVE REFRIGERANTS}

The following two sections summarize the findings from the HPDM modeling simulations. Performance for five alternative refrigerants and the baseline refrigerant (R-134a) are presented in terms of FHR, UEF and COP for the heat pump. Some additional results are shown in the appendix for further information. 


\subsection{PARAMETERS FOR PERFORMANCE EVALUATION}

Because the ultimate goal of the analysis was to obtain the maximum possible efficiency a combination of parameters was considered which can directly impact the performance. A summary of the parameters follows:

1-Tank insulation effectiveness: Two representative insulation effectiveness values were considered for the heat loss from the tank. An effectiveness of $90 \%$ is the case where tank loses $10 \%$ of the energy input to the water whereas $95 \%$ is where half as much energy is lost through tank wall and insulation material to the environment. This essentially accounts for two values for the resistance to heat loss.

2-Condenser wrap pattern: Two different wrap configurations were considered for analysis. The counterflow pattern represents the flow of the refrigerant entering from the top section of the tank and moving downwards. In the parallel flow configuration, the refrigerant enters close the middle part of the tank and moves upwards and then comes back to the middle section to continue downwards (identical to the pattern used by the prototype GeoSpring systems evaluated in prior projects).

3-Evaporator size: Two different evaporator sizes were considered. 1Evap represents the size of baseline evaporator (11-inch by 13-inch face dimension with a thickness of 1.732-inch) whereas 2Evap is an evaporator with two times the size of the baseline heat exchanger (twice the heat transfer surface area), air flow rate and evaporator blower power consumption.

4-Condenser tube size: In order to account for the impact of the condenser tube size on the overall performance of the system, two different tube nominal diameters were considered, 0.31-inch (tube diameter for the baseline) and 0.5-inch. The larger tube diameter helped to minimize the pressure drop, as for some of the alternative refrigerants considered for parametric analysis, the saturation temperature drop due to the refrigerant pressure drop through condenser tube becomes quite large with the smaller tube size and hence lowers the performance. With the larger tube diameter, the pressure drops for those refrigerants smaller and stays within desired limits. However, increasing the tube size also has the negative effect of reducing the refrigerant side heat transfer coefficient due to decreasing mass flux. 


\subsection{FIRST HOUR RATING ANALYSIS FOR VARIOUS REFRIGERANTS}

The first critical step for the performance analysis was to establish the first hour rating (FHR) as this information determines the water draw pattern and both COP and UEF factors depend on that. Figure 5 presents the FHR for different refrigerants at different design parameters. It's obvious that for all different cases the FHR stayed between 57 and 65 gallons. This made the situation easier as according to Table 2all cases suggested that a medium usage draw should be used for further analysis.

As mentioned above, FHR is a direct indication of the system capacity. A larger FHR indicates a superior system capacity. It can be observed from the analysis that R1234yf consistently shows a comparable FHR when compared with baseline R134a values between 61 and 63 gallons, whereas R1234ze has an average FHR close to 60 gallons. Overall evaporator size and the condenser tube size are dominant factors but the response of different refrigerants to these parameters varies.

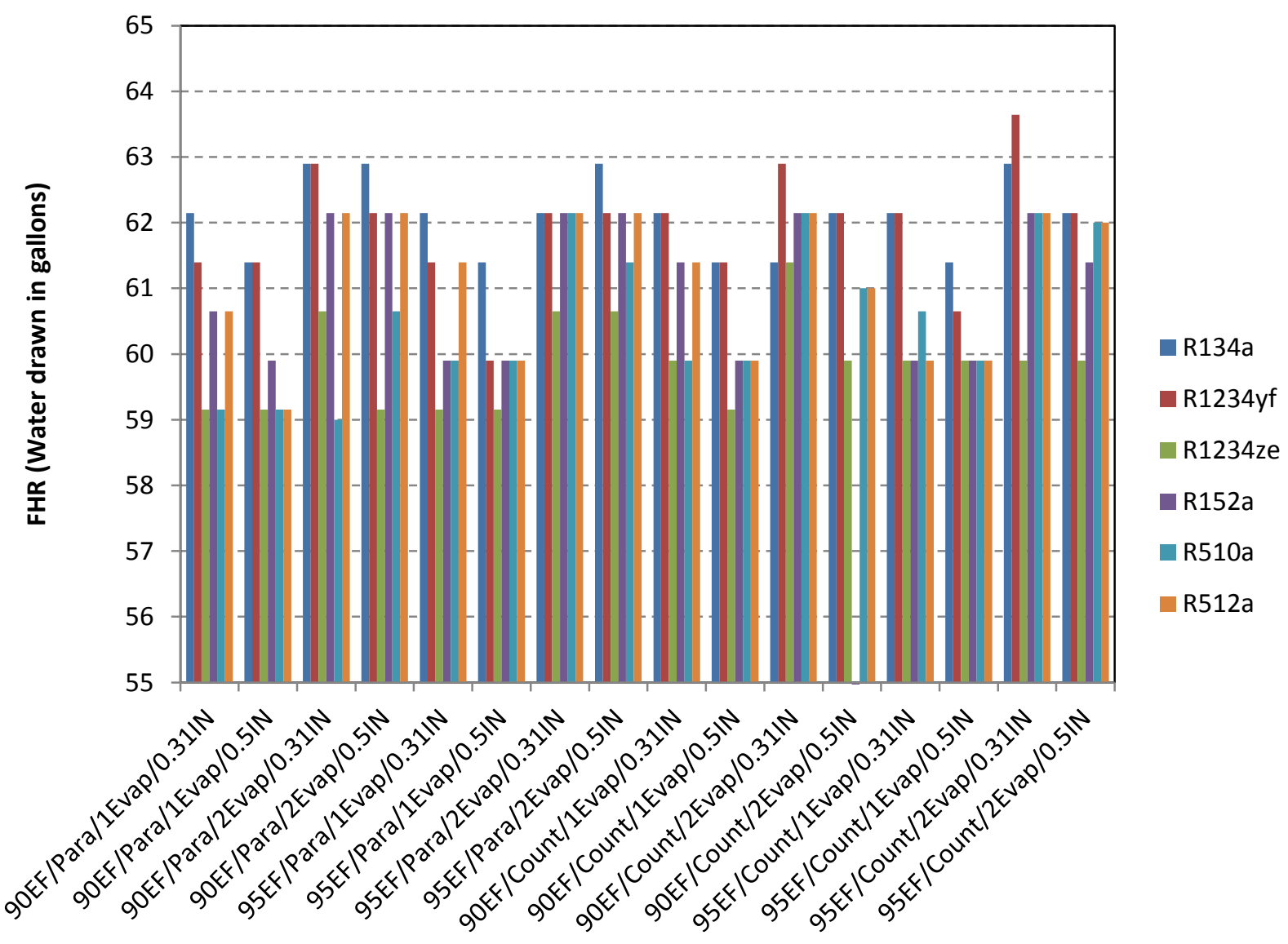

Figure 5. First Hour Rating for different refrigerants with varying design options 


\subsection{UNIFIED ENERGY FACTOR (UEF) ANALYSIS FOR VARIOUS REFRIGERANTS}

Unified Energy Factor (UEF) is a direct measure of the system efficiency. A larger UEF denotes a better performance. Figure 6 presents the 24 hour UEF for different refrigerants as the design parameters vary. It is obvious that design parameters play a critical role based on the selection of wrap pattern, evaporator size and condenser tube size. There is a wide range of UEF varying from lowest average level of 2.97 to highest average of 3.64. A 0.5 -inch diameter parallel wrap condenser with smaller evaporator and 90\% tank insulation effectiveness results in the least UEF whereas a 0.31 -inch diameter parallel wrap condenser with larger evaporator and 95\% tank insulation effectiveness provides the best UEF among other portions.

It is also important to note that, even though the relative values for UEF for different refrigerants don't vary much, R1234ze shows the consistently lowest UEF among all refrigerants. For all other alternative refrigerants performance is in the ballpark of the baseline refrigerant, R-134a, except R1234yf which shows slightly lower UEF for some design options.

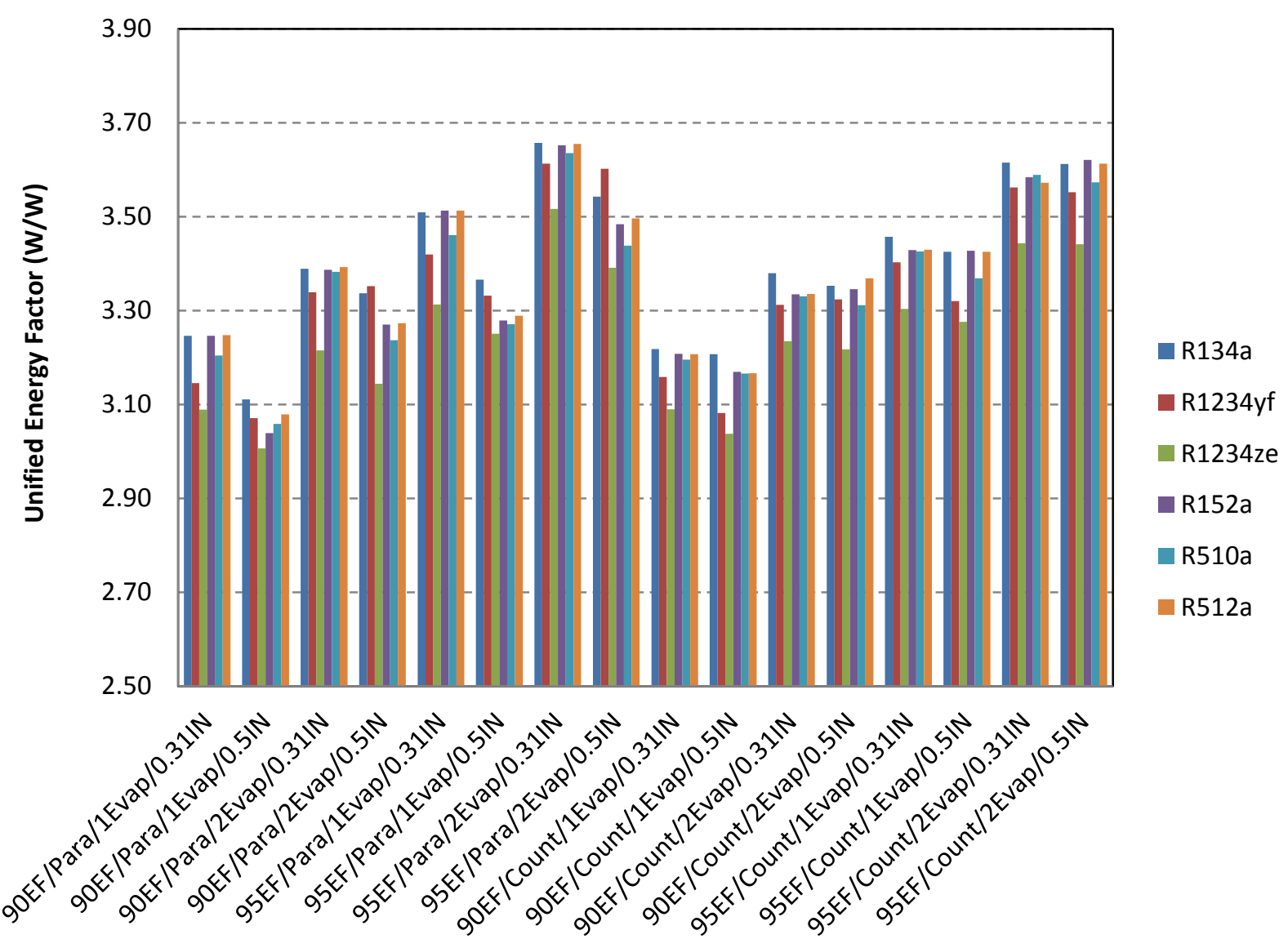

Figure 6. Unified Energy Factor (UEF) for different refrigerants with varying design options 


\subsection{COP ANALYSIS FOR VARIOUS REFRIGERANTS}

COP is typical parameter used to describe the efficiency of heat pump. It is important to recognize that COP unlike UEF represents the efficiency of heat pump only and can't be used to indicate the performance of whole system. However, this is still an important parameter to consider as it shows the stand-alone performance of heat pump.

Figure 7 presents COP for different design options. The performance somewhat follows the same trend as for UEF. The best COP is obtained for parallel wrap pattern with larger evaporator and 0.31-inch condenser tube diameter with 95\% tank insulation effectiveness. When the individual performance of different refrigerants is compared for a specific design option, it is obvious that R152a, R510a and R512a outperform R1234yf and R1234ze and the COP is comparable to the baseline except one case when parallel wrap pattern is deployed with larger evaporator and 0.5-inch condenser tube diameter and $95 \%$ tank heat loss factor.

It's also important to note the relative difference between COPs for same design options (evaporator size, wrap pattern and condenser tube diameter) and different insulation effectiveness. A relatively lower COP for $90 \%$ insulation effectiveness is associated with relatively hotter supply water. A higher supply water temperature for $90 \%$ thermal insulation (Figure 8) results because of the control mechanism to turn ON and OFF the heat pump and ultimately lowers the system COP. Due to the heat lost because of the worse thermal insulation the heat pump run time is increased which ultimately leads to a higher supply temperature.

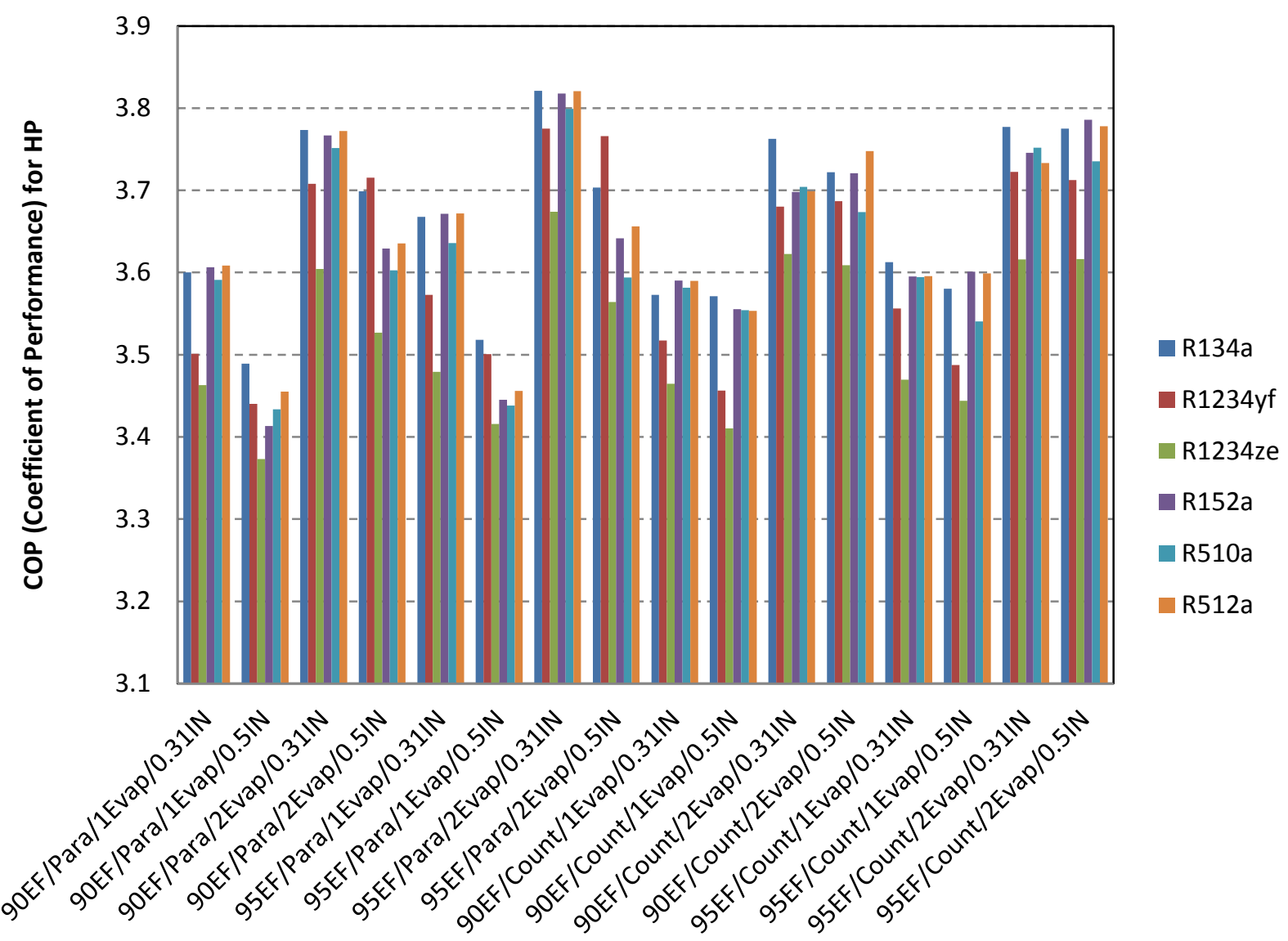


Figure 7. Coefficient of Performance (COP) for different refrigerants with varying design options

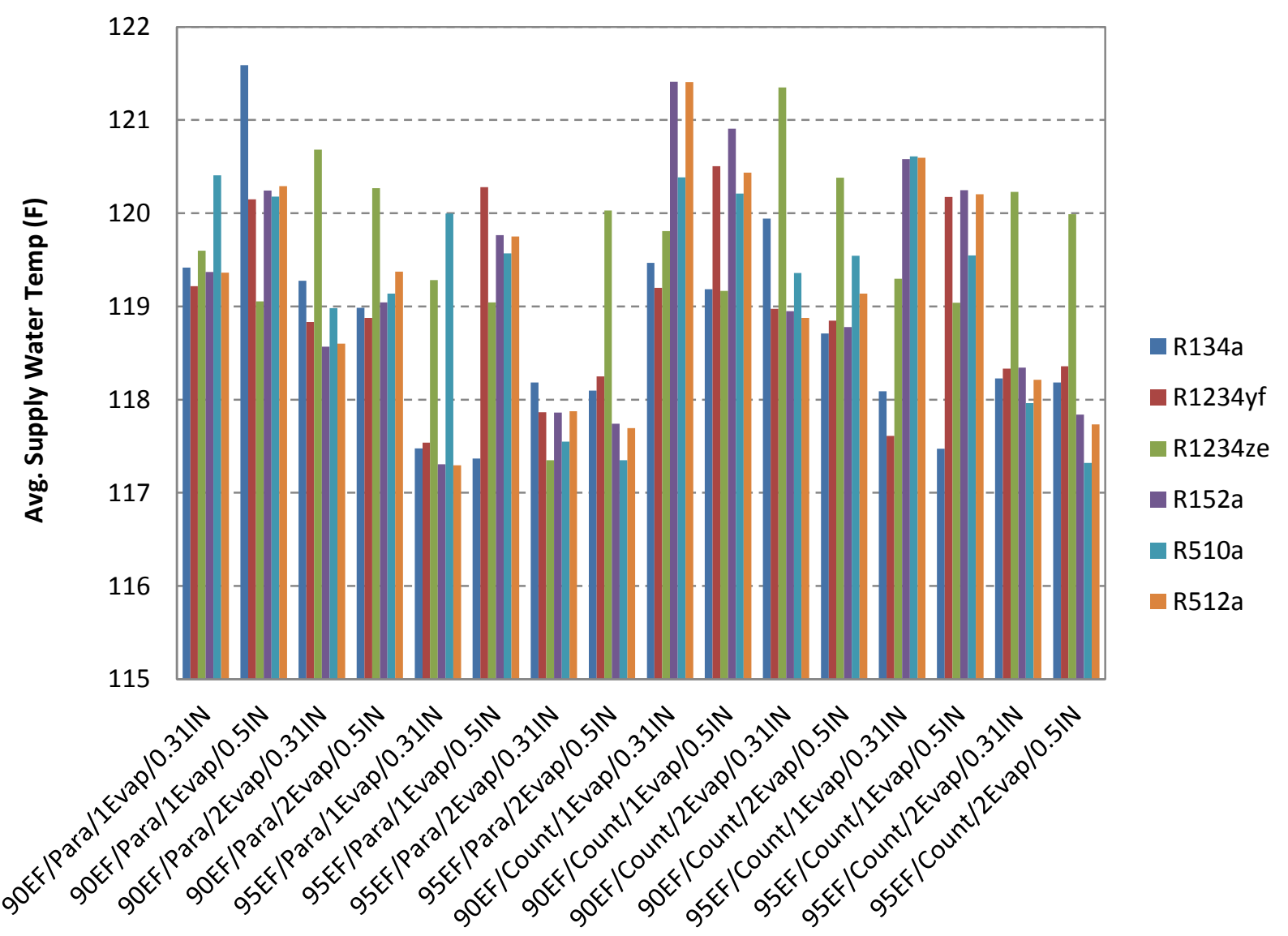

Figure 8. Average supply water temperature for different refrigerants with varying design options

\section{COMPARISON OF PERFORMANCE TO CURRENT ENERGY STAR HPWH SYSTEMS}

Heat pump water heaters are the most efficient type of electric water heater available and are used as the best available option among electric-resistance WHs. Since the emergence of the technology, multiple high efficiency HPWH products have been introduced by manufacturers. While examining the performance of alternative refrigerants, it is important to review the performance of existing products. The following table gives a relative comparison provided by FEMP (Energy Star, 2016).

Table 4. Typical performance for various HPWHs in market

\begin{tabular}{|l|l|l|l|}
\hline Performance & Best Available & Energy Star & Less Efficient \\
\hline Energy factor & 3.39 & 2.20 & 0.95 \\
\hline Annual energy use & $958 \mathrm{kwh}$ & $1476 \mathrm{kwh}$ & $3437 \mathrm{kwh}$ \\
\hline Annual energy cost & $\$ 89$ & $\$ 137$ & $\$ 319$ \\
\hline Lifetime energy cost & $\$ 1000$ & $\$ 1541$ & $\$ 3587$ \\
\hline Lifetime cost saving & $\$ 2587$ & $\$ 2046$ & - \\
\hline
\end{tabular}


For the analysis presented in Table 4, annual energy cost is calculated based on an assumed electricity price of $\$ 0.09 / \mathrm{kWh}$, which is the average electricity price at federal facilities and the lifetime energy cost includes the future electricity price trends and a 3\% discount rate. Lifetime cost savings are the difference between the lifetime energy cost of the less efficient model and the lifetime energy cost of the Energy Star model or best available model. The performance for Best Available Model is based on the April 2016 ENERGY STAR-Qualified products list. The following table presents a more comprehensive and recent listing of the Energy Factors for energy efficient products identified by AHRI. Most of such products generally use electric heat as the auxiliary heating source.

Table 5. Current best HPWH models in market and associated UEFs (AHRI certified products)

\begin{tabular}{|c|c|c|c|}
\hline AHRI Number & OEM Name & Model Number & Unified Energy Factor \\
\hline 9060121 & A.O. SMITH WATER PRODUCTS CO. & FPTU-50 120 & 3.24 \\
\hline 8215355 & AMERICAN WATER HEATER & HPHE10250H045DV 120 & 3.24 \\
\hline 7599404 & BRADFORD WHITE CORP. & RE2H50R10B-1NCWT & 3.39 \\
\hline 7551743 & GE APPLIANCES & GEH50DFEJSR* & 3.25 \\
\hline 8797247 & GE APPLIANCES & GEH50DHEKSC* & 3.39 \\
\hline 8215364 & GSW WATER HEATERS & G1050TDE-HPHE-45 120 & 3.24 \\
\hline 9060134 & GSW WATER HEATERS & G1050TDE-HPHE-45N 120 & 3.24 \\
\hline 9060135 & JOHN WOOD & JW1050TDE-HPHE-45N 120 & 3.24 \\
\hline 8215362 & LOCHINVAR, LLC & HPA051KD 120 & 3.24 \\
\hline 9060124 & RELIANCE WATER HEATER & 6-50-DHPHT 120 & 3.24 \\
\hline 9952296 & RHEEM SALES & XE50T10HD50U0 & 3.50 \\
\hline 8215363 & SEARS BRANDS MANAGEMENT & 153.592500 & 3.24 \\
\hline 9060122 & STATE WATER HEATERS & HP6-50-DHPT 120 & 3.24 \\
\hline 9060132 & U.S. CRAFT MASTER & HPHE2K50HD045VUN 120 & 3.24 \\
\hline
\end{tabular}

\section{CONCLUSIONS}

Based on the findings described above, it can be concluded that refrigerants with low GWP can be utilized as R-134 substitutes for HPWH application. No substantial modification of the system configurations is required to achieve comparable performance to the baseline system deploying R-134a. Comparing the relative performance of different substitutes, all refrigerants except R-1234ze show marginal performance difference relative to the baseline based on parameters such as UEF, FHR, and $\mathrm{COP}$ and should be considered for further lab testing.

\section{ORNL RECOMMENDATIONS}

Based on the findings described above, ORNL recommends that the project pass scoping analysis and proceed to the next stage, Exploratory Development, through lab proof of concept validation. As the next step for concept validation, appropriate industry will be contacted for system level validation through CRADA partnership. 


\section{ACKNOWLEDGEMENTS}

The authors acknowledge the support provided by Dr. Omar Abdelaziz in the preparation of the report. This work was sponsored by the U.S. Department of Energy Building Technology Office (DOE/BTO) under Contract No. DE-AC05-00OR22725 with UT-Battelle, LLC; technology development manager Mr. Antonio Bouza.

\section{REFERENCES}

ANSI/AHRI Standard 540-99, 2010, "Positive Displacement Refrigerant Compressors and Compressor Units", Air Conditioning and Refrigeration Institute, Arlington, VA

ANSI/AHRI Standard 340/360, 2010, "Performance Rating of Commercial and Industrial Unitary AirConditioning and Heat Pump Equipment", Air-Conditioning, Heating, and Refrigeration Institute, Arlington, VA

AHRI certified products (https://www.ahridirectory.org/ahridirectory/pages/rwh/defaultSearch.aspx)

Baxter, V. D., R. W. Murphy, C. K. Rice, and R. L. Linkous, 2016. High Efficiency Water Heating Technology Development - Final Report: Part I, Lab/Field Performance Evaluation and Accelerated Life Testing of a Hybrid Electric Heat Pump Water Heater (HPWH), ORNL/ TM-2016/104.

V. D. Baxter, R. W. Murphy, C. K. Rice, B. Shen, Z. Gao, 2011. Analysis of Highly Efficient Electric Residential Heat Pump Water Heaters for Cold Climates, ORNL/TM-2011/278.

Braun. J.E., Klein. S.A, and Mitchell, J.W., 1989, "Effectiveness models for cooling towers and cooling coils", ASHRAE Transactions, 95(2), pp. 164-174.

EIA (US Energy Information Administration), 2015. 2012 Commercial Buildings Energy Consumption Survey (CBECS).

Churchill, S.W., and Chu, H.H.S., "Correlating Equations for Laminar and Turbulent Free Convection from a Horizontal Cylinder," Int. J. Heat Mass Transfer, 18, 1049, 1975.

Dabiri, A. E. and C.K. Rice, 1981 "A Compressor Simulation Model with Corrections for the Level of Suction Gas Superheat," ASHRAE Transactions, Vol. 87, Part 2, pp.771-782.

ENERGY STAR Product Specification for Residential Water Heaters: Partner Commitments, Office of Energy Efficiency and Renewable Energy.

Kedzierski, M. A., and Choi J. Y., "A generalized pressure drop correlation for evaporation and condensation of alternative refrigerants in smooth and micro-fin tubes" NISTIR 6333, 1999

Murphy, R. W., V. D. Baxter, E. A. Vineyard, and R. L. Linkous, 2011, "Drop-in Evaluation of Refrigerant R1234yf in a Residential Integral Heat Pump Water Heater," Proceedings of the $10^{\text {th }}$ International Energy Agency Heat Pump Conference. 
Shen, B. and Rice, C. K., 2014, HVAC System Optimization with a Component Based System Model New Version of ORNL Heat Pump Design Model, Purdue HVAC/R Optimization Short Course, International Compressor \& refrigeration conferences at Purdue, Lafayette, USA, 2014.

Thome J.R. and Jean Ei Hajal, 2002, "On recent advances in modelling of two-phase flow and heat transfer", 1st Int. Con. on Heat Transfer, Fluid Mechanics, and Thermodynamics, Kruger Park, south Africa TJ1, 8-10 April.

Thome J. R., J. El Hajal, and A. Cavallini, 2003a, "Condensation in horizontal tubes, part 1: two-phase flow pattern map", International Journal of Heat and Mass Transfer, 46(18), Pages 3349-3363.

Thome J. R., J. El Hajal and A. Cavallini, 2003b, "Condensation in horizontal tubes, part 2: new heat transfer model based on flow regimes", International Journal of Heat and Mass Transfer, 46(18), Pages 3365-3387.

US Code of Federal Regulations. 2010. "Uniform Test Methods for Measuring the Energy Consumption of Water Heaters," Code of Federal Regulations, Title 10, Chapter II, Volume 3, Part 430, Subpart B, Appendix E.

Water Heater Test Procedure Rulemaking: Development Testing Preliminary Report Energy Conservation Program For Consumer Products and Certain Industrial Equipment: Residential and Light Commercial Water Heaters, U.S. Department of Energy, 2013.

Wang, C. C., 2001, "A Comparative Study of Compact Enhanced Fin-and-Tube Heat Exchangers", Int. J. Heat and Mass Transfer, Vol. 44, pp. 3565-3573. 
APPENDIX A. ADDITIONAL PERFORMANCE EVALUATION PARAMETERS 


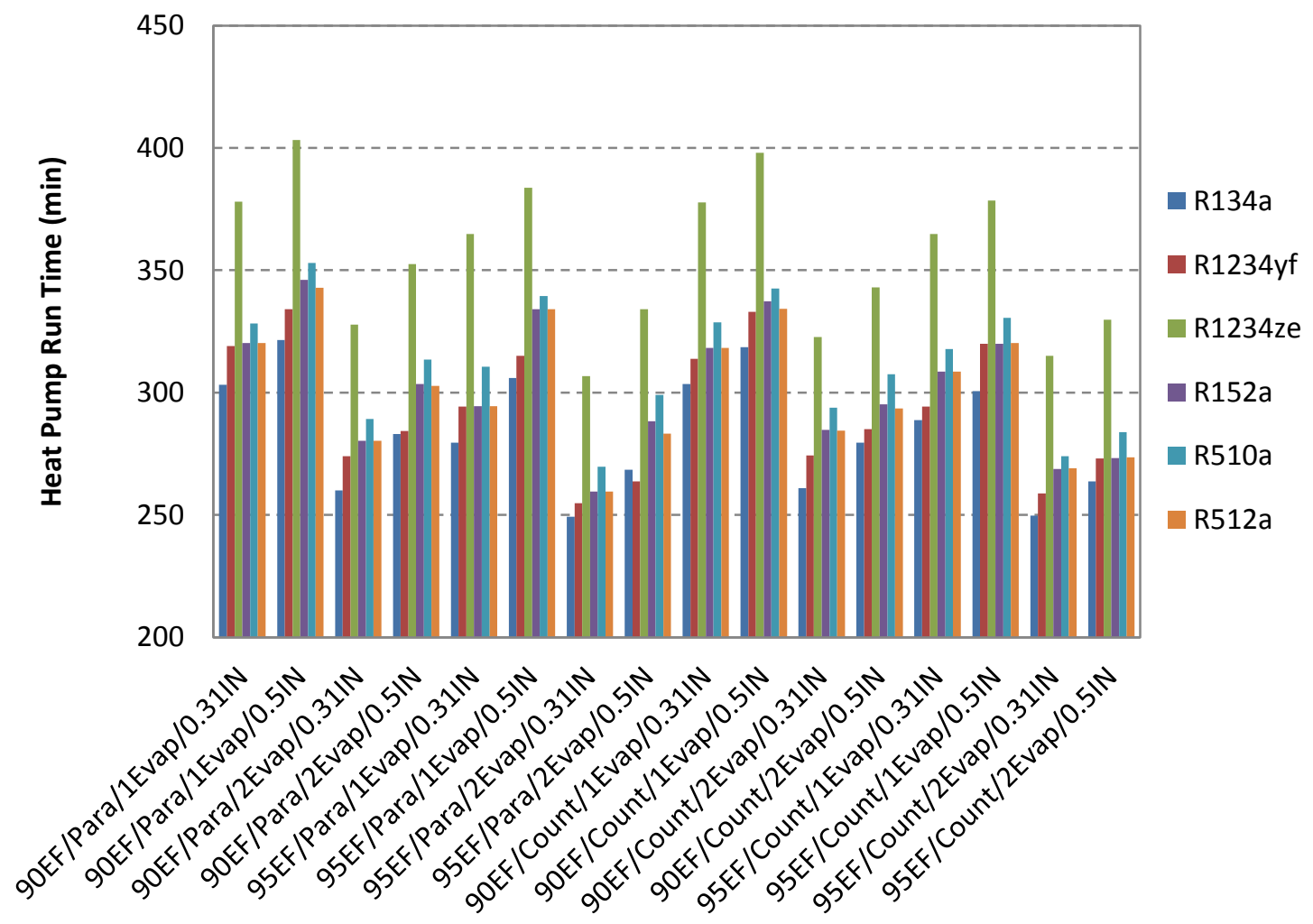

Figure 9. Heat pump run time for different refrigerants with varying design options

Figure 9 presents the total heat pump run time during a 24-hour UEF test. For any design selection R1234ze has the largest run time. This is a direct indication of lower capacity for the R1234ze. For all other refrigerants the heat pump run time is comparable to the baseline R134a. 


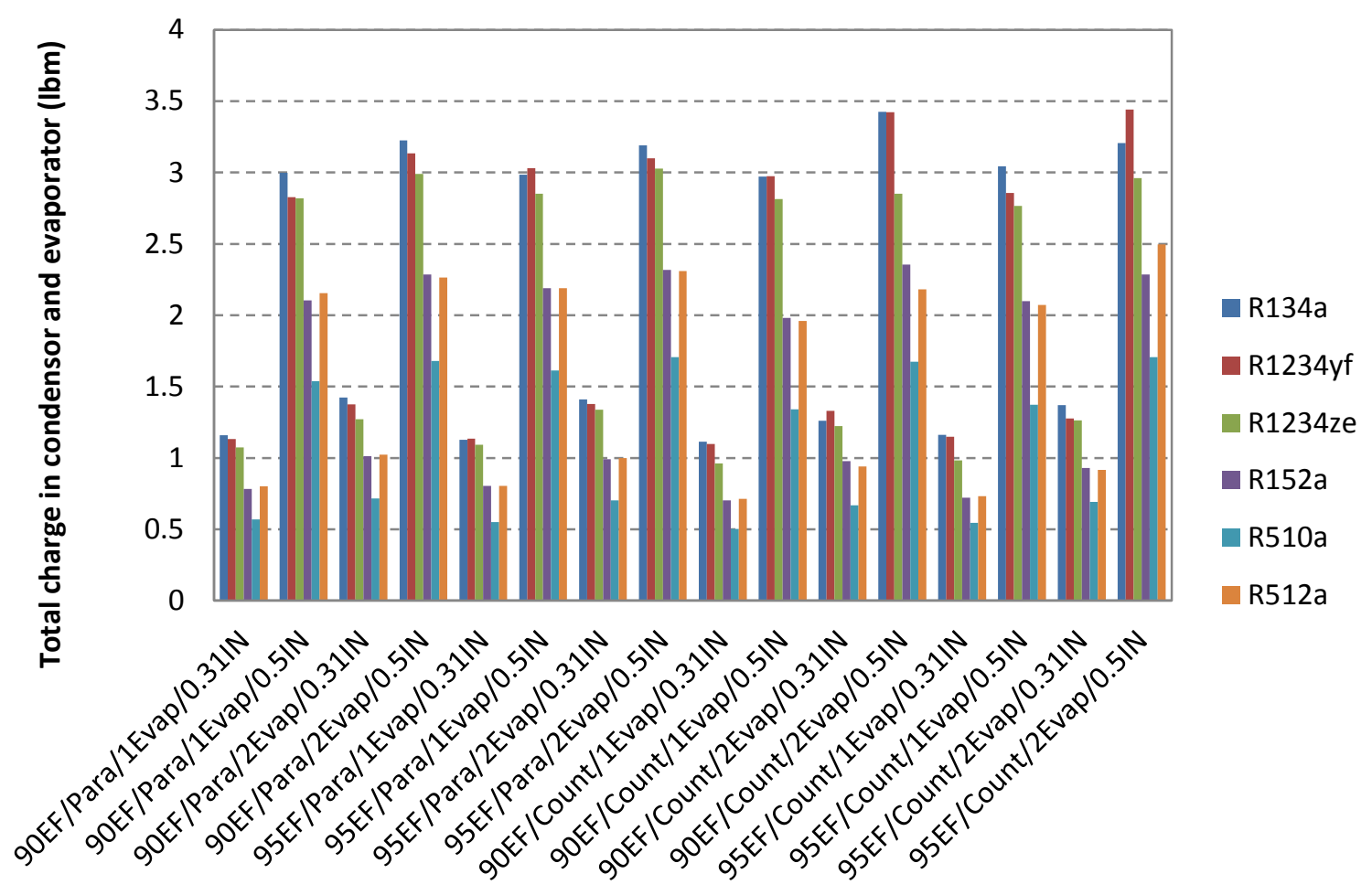

Figure 10. Total charge in condenser and evaporator for different refrigerants with varying design options

Total system charge is a critical parameter and there has been a continuous effort to minimize this as it adds to cost. Another important factor is the safety issue when using the flammable refrigerants. Figure 10 shows total charge in evaporator and condenser. Among different design options, 0.5 -inch condenser tube diameter has relatively larger total charge. However, for any specific design selection, total charge is least for R510a and is higher for the baseline (R134a), R1234yf and R1234ze. 


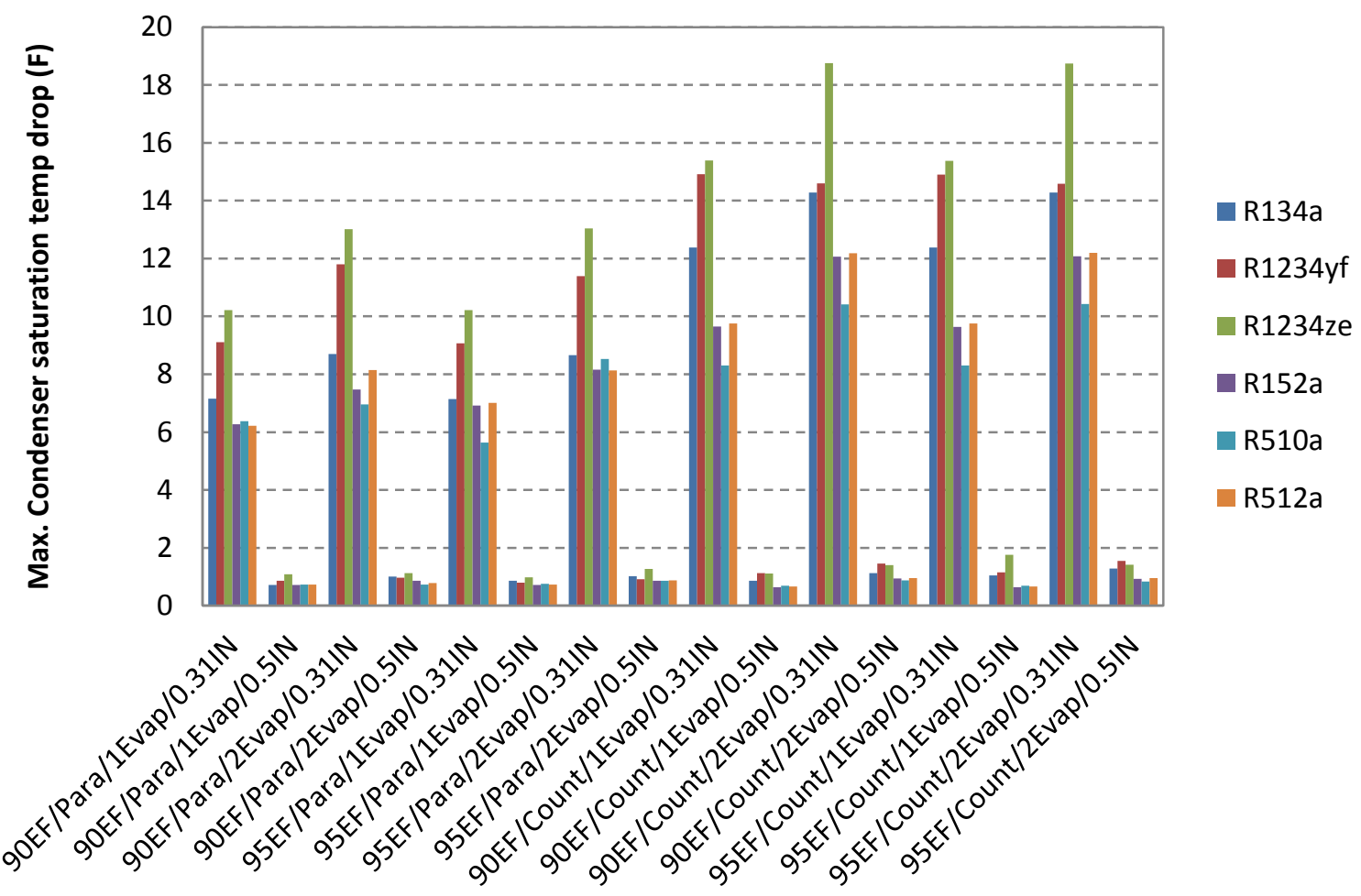

Figure 11. Maximum condenser saturation temperature drop for different refrigerants with varying design options

Figure 11 presents the maximum condenser saturation temperature drop. For better heat transfer performance, a smaller temperature drop is desired which is the case for all design options with 0.5 -inch condenser tube diameter. However, the larger tube diameter adds to the total cost and adversely impact the tube side heat conductance due to the smaller velocity of refrigerant when compared to 0.31 -inch tube diameter. For any specific design selection R1234ze have the highest temperature drop and R1234yf is second in the list. All other refrigerants including baseline have comparable values. 


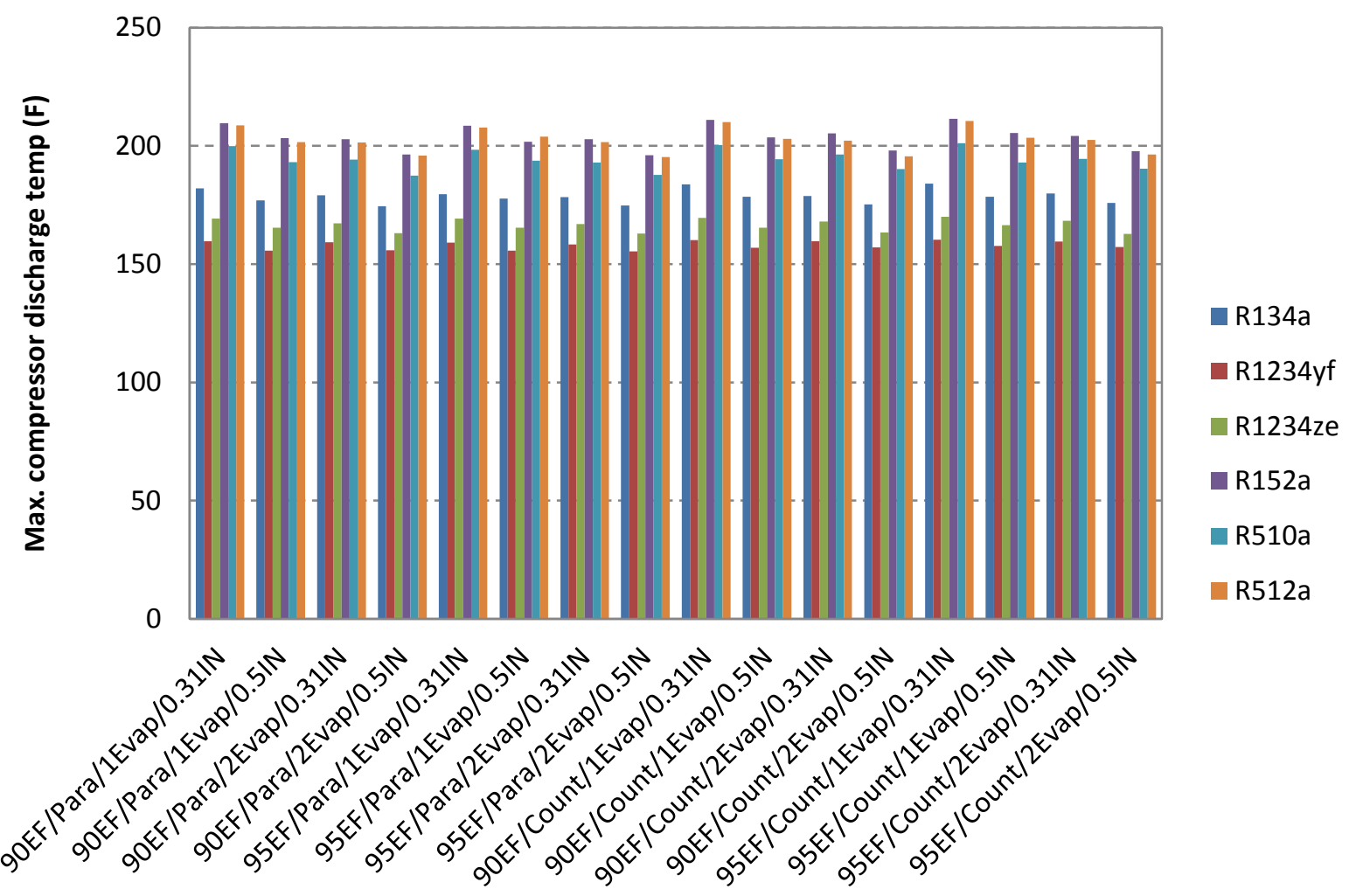

Figure 12. Max compressor discharge temperature for different refrigerants with varying design options

For a drop-in-replacement study it is desirable to have a comparable and preferably lower compressor discharge temperature for alternative refrigerants as this ensure a similar compressor with existing lubrication can fulfill the purpose. Figure 12 indicates that max compressor discharge temperature is about 20-25 F lower for R1234yf and for R1234ze compared to the baseline line refrigerant (R134a) and on average 20-25 F higher for R152a, R510a and R512a. As such the use of R152a, R510a and R512a may require re-designing of compressor with compatible lubrication. 


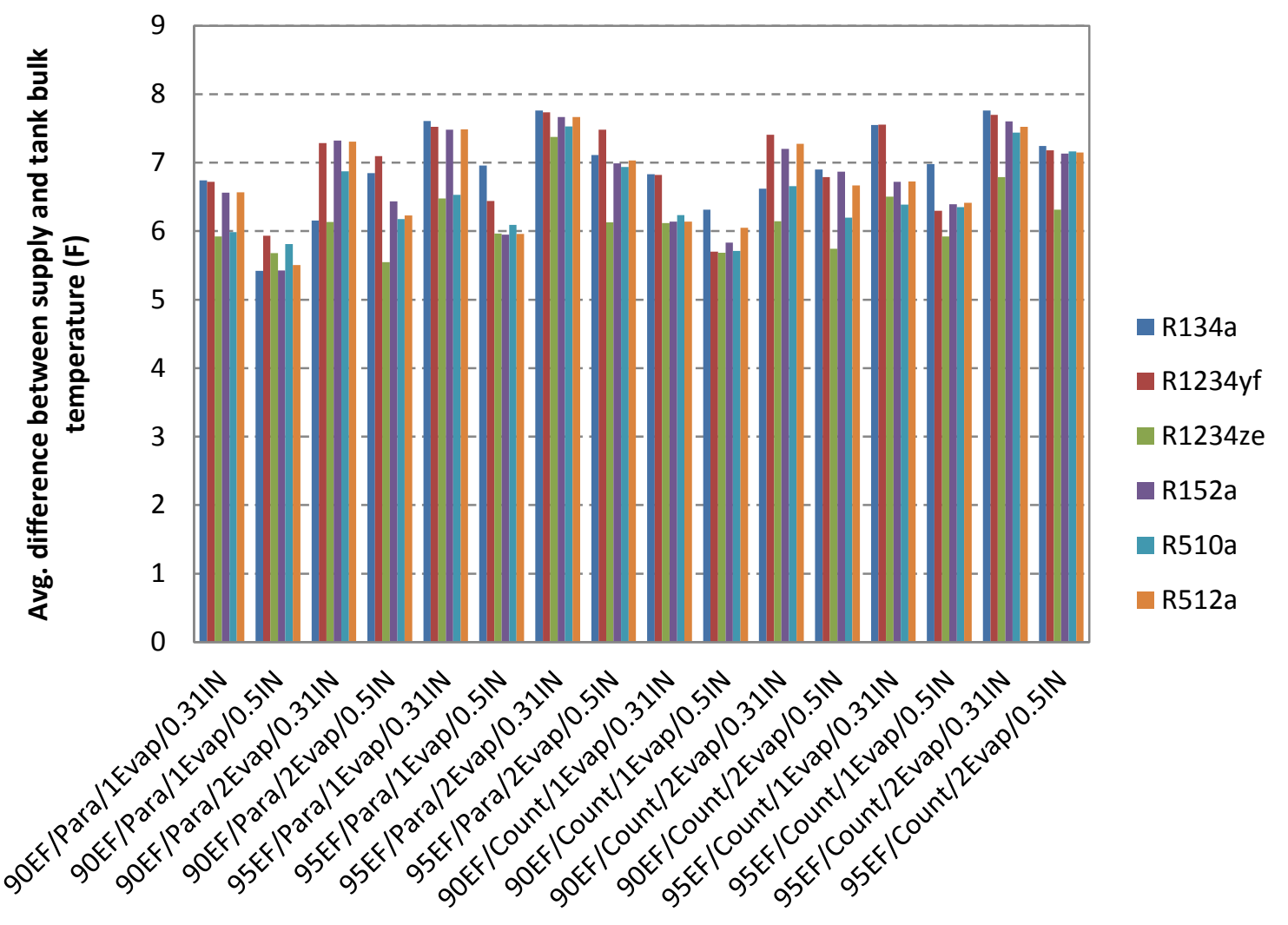

Figure 13. Average difference between supply and tank bulk temperature for different refrigerants with varying design options

Figure 13 presents the relative water stratification for different refrigerants and design selections. There is no consistent trend when different refrigerants are compared for a specific design selection; however the relative water temperature difference is lowest for R1234ze on average. Temperature stratification is maximum for a parallel wrap pattern, larger evaporator and 0.31-inch condenser tube diameter with $95 \%$ insulation effectiveness. 